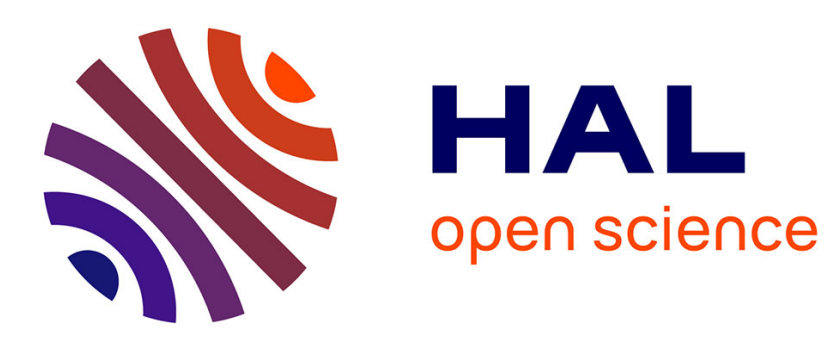

\title{
Prediction of acoustic properties of parallel assemblies by means of transfer matrix method
}

Kévin Verdière, Raymond Panneton, Saïd Elkoun, Thomas Dupont, Philippe Leclaire

\section{- To cite this version:}

Kévin Verdière, Raymond Panneton, Saïd Elkoun, Thomas Dupont, Philippe Leclaire. Prediction of acoustic properties of parallel assemblies by means of transfer matrix method. 21st International Congress on Acoustics, Acoustical Society of America, Jun 2013, Montréal, Canada. 10.1121/1.4799562 . hal-01329919

\section{HAL Id: hal-01329919 https://hal.science/hal-01329919}

Submitted on 9 Jun 2016

HAL is a multi-disciplinary open access archive for the deposit and dissemination of scientific research documents, whether they are published or not. The documents may come from teaching and research institutions in France or abroad, or from public or private research centers.
L'archive ouverte pluridisciplinaire HAL, est destinée au dépôt et à la diffusion de documents scientifiques de niveau recherche, publiés ou non, émanant des établissements d'enseignement et de recherche français ou étrangers, des laboratoires publics ou privés. 


\section{Proceedings of Meetings on Acoustics}
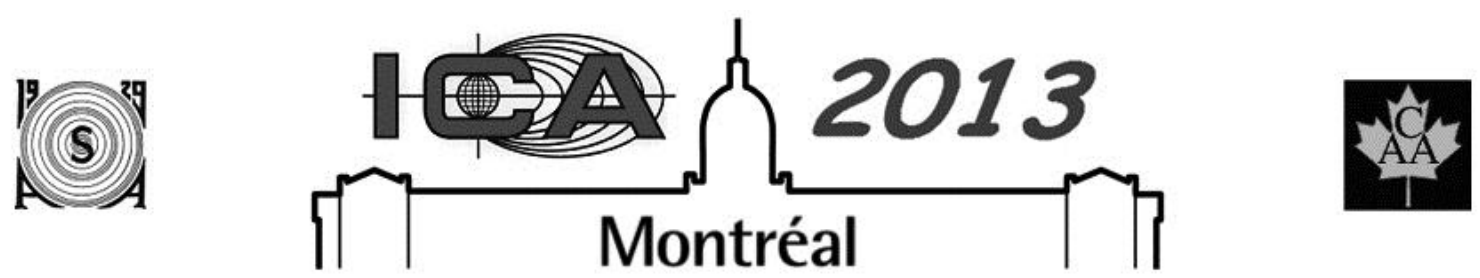

ICA 2013 Montreal

Montreal, Canada

2 - 7 June 2013

Structural Acoustics and Vibration

Session 1pSA: Measurement and Modeling of Structures with Attached Noise Control Materials II

\section{1pSA2. Prediction of acoustic properties of parallel assemblies by means of transfer matrix method}

Kévin Verdière*, Raymond Panneton, Saïd Elkoun, Thomas Dupont and Philippe Leclaire

\footnotetext{
*Corresponding author's address: Department of Mechanical Engineering, GAUS, Université de Sherbrooke, Sherbrooke, J1K2R1, Québec, France, kevin.verdiere@usherbrooke.ca

The Transfer Matrix Method (TMM) is used conventionally to predict the acoustic properties of laterally infinite homogeneous layers assembled in series to form a multilayer. In this work, a parallel assembly process of transfer matrices is used to model heterogeneous materials such as patchworks, acoustic mosaics, or a collection of acoustic elements in parallel. In this method, it is assumed that each parallel element can be modeled by a $2 \times 2$ transfer matrix, and no diffusion exists between elements. The method is validated by comparison with finite element method (FEM). Then, an overview of the possibilities, such as the combination of series and parallel matrices, the sound absorption coefficient and the transmission loss of a parallel array of resonators or three-dimensional geometries is presented and discussed.
}

Published by the Acoustical Society of America through the American Institute of Physics 


\section{INTRODUCTION}

In our modern society, noise pollution is a serious concern as it has profound impact on economy, health and productivity. Thus, the need to reduce noise has led to the development of a wide range of sound barriers and/or absorbing materials. Among the most used sound-absorbing materials, porous materials exhibit, in general, fairly high sound absorption coefficients. However, their acoustic performances are highly dependent upon frequency and are still poor at low frequency. To overcome this problem, different porous materials can be stacked to obtain porous multilayered materials. Moreover and knowing the properties of each layer, the acoustical properties of multilayered materials can easily be obtained using the transfer matrix method (TMM) for materials stacked in series ${ }^{1}$. In contrast, for parallel stacking of materials, the Finite Element Method (FEM) is the most general approach to derive acoustic properties. For instance, acoustic properties of micro-perforated panels with different parallel cavity sizes ${ }^{2}$, parallel tubes in mufflers ${ }^{3}$, parallel periodic structures ${ }^{4-5}$ and parallel assembly of porous material ${ }^{6}$ can $^{\text {be obtained }}$ using FEM simulations or analytical models developed for specific cases and, therefore, limited to few applications and difficult to generalize. As far as we know, no study was published yet using TMM for deriving the acoustic properties of multilayered materials made of parallel stacking of various materials and structures. Recently, the authors have presented an extension to TMM to deal with parallel assembly of transfer matrices ${ }^{7}$. This parallel assembly allows the study of acoustic materials which are in the form of mosaics or patchworks.

The aim of this paper is to first recall this extension of the TMM to account for the assembly of materials (or acoustic elements) in parallel and series, and to apply to three cases not yet published: (1) a patchwork of 6 materials under oblique incidence; (2) a parallel versus serial arrangements of perforated plates, and (3) a 3D assembly of melamine foam spheres in a cubic lattice. The results are presented in terms of sound absorption coefficient and transmission loss, and compared to finite element simulations. It is found that both methods give similar results.

\section{THEORY}

The Transfer Matrix Method (TMM) is a powerful method to predict sound absorption and sound transmission loss of multilayered laterally infinite materials stacked in series ${ }^{1}$. In this paper, the extension of the TMM to parallel assembly of finite size materials is recalled ${ }^{7}$. The key assumptions underlying the method are: 1) only plane waves propagate upstream and downstream the construction; 2) only normal incidence plane waves propagate in the construction; 3) no pressure diffusion exists between adjacent parallel elements, 4) the wavelength is much larger than the periodic elementary patchwork, and 5) each element can be represented by a $2 \times 2$ transfer matrix

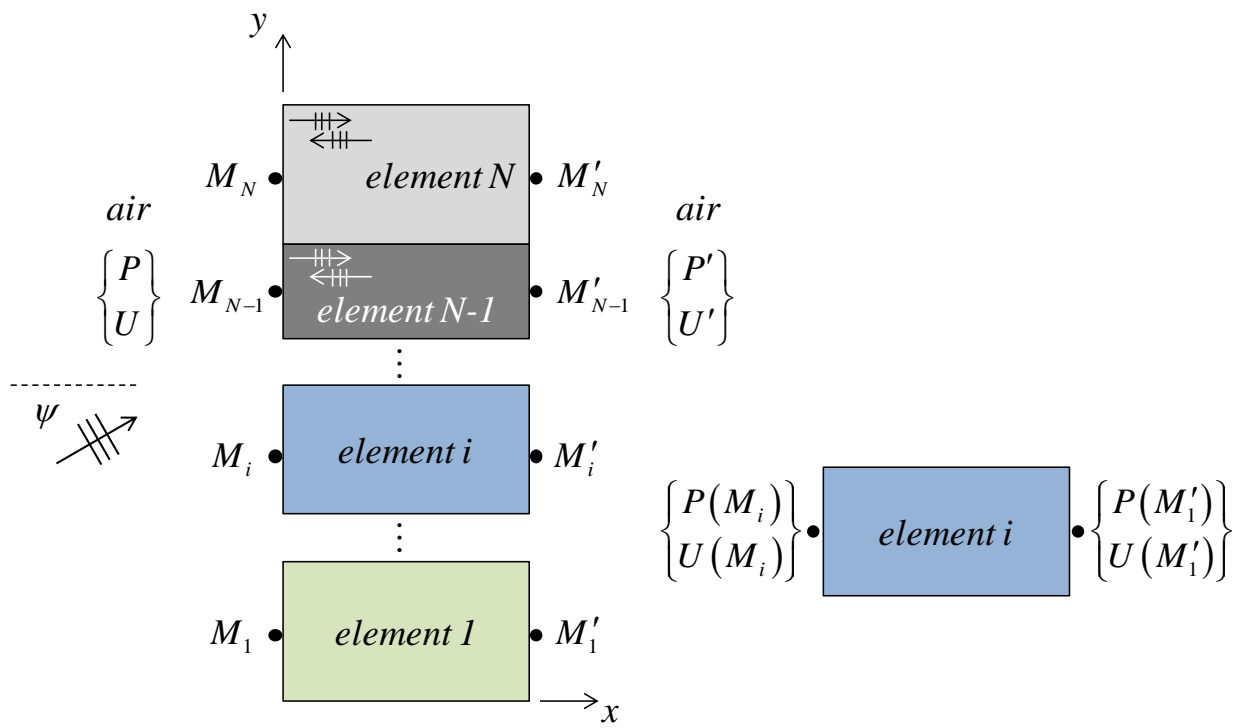

FIGURE 1. Plane wave impinging on the studied parallel construction made of $N$ parallel elements. The arrows represent plane waves. 
Figure 1 shows a parallel arrangement of $N$ elements. These elements can be porous materials, perforated plates, a measured $2 \times 2$ transfer matrix obtained by a three microphones method ${ }^{8}$ or whatever which can be expressed by $2 \times 2$ transfer matrix. The case where all elements are open to air on the upstream and downstream sides is only studied. The other case (e.g. closed downstream) can be formulated following the same steps. Following assumption 2 , each element may be seen as being locally reacting and a waveguide along the $\mathrm{x}$-axis. Each element can consist of a single material or a stack of materials in series. To link the acoustic pressures $P$ and the $x$-component $U$ of the acoustic velocities in the air on either side of element $i$, the following $2 \times 2$ transfer matrix relation is used

$$
\left\{\begin{array}{l}
P\left(M_{i}\right) \\
U\left(M_{i}\right)
\end{array}\right\}=\mathbf{T}_{i}\left\{\begin{array}{l}
P\left(M_{i}^{\prime}\right) \\
U\left(M_{i}^{\prime}\right)
\end{array}\right\}=\left[\begin{array}{ll}
t_{i, 11} & t_{i, 12} \\
t_{i, 21} & t_{i, 22}
\end{array}\right]\left\{\begin{array}{l}
P\left(M_{i}^{\prime}\right) \\
U\left(M_{i}^{\prime}\right)
\end{array}\right\}
$$

where $t_{i, m n}$ are the coefficients of transfer matrix $\mathbf{T}_{i}$.

Since the elements are in parallel, it is more convenient to work with admittances. Consequently, Eq. (1) can be written in terms of an admittance matrix $\mathbf{Y}_{i}$ as follows

$$
\left\{\begin{array}{l}
U\left(M_{i}\right) \\
U\left(M_{i}^{\prime}\right)
\end{array}\right\}=\left[\begin{array}{ll}
y_{i, 11} & y_{i, 12} \\
y_{i, 21} & y_{i, 22}
\end{array}\right]\left\{\begin{array}{l}
P\left(M_{i}\right) \\
P\left(M_{i}^{\prime}\right)
\end{array}\right\}=\frac{1}{t_{i, 12}}\left[\begin{array}{cc}
t_{i, 22} & t_{i, 21} t_{i, 12}-t_{i, 22} t_{i, 11} \\
1 & -t_{i, 11}
\end{array}\right]\left\{\begin{array}{l}
P\left(M_{i}\right) \\
P\left(M_{i}^{\prime}\right)
\end{array}\right\}
$$

Following assumptions 1 and 4, since only plane waves propagate in the surrounding air, at a given distance $x$ of the patchwork the pressure is uniform over the upstream and downstream open-faces in the air. Similarly, continuity of flow rate is preserved at the open interfaces. These continuity conditions can be written as:

$$
\left\{\begin{array}{l}
P\left(M_{i}\right) \\
P\left(M_{i}^{\prime}\right)
\end{array}\right\}=\left\{\begin{array}{c}
P \\
P^{\prime}
\end{array}\right\} \text { and }\left\{\begin{array}{c}
U \\
U^{\prime}
\end{array}\right\}=\left\{\begin{array}{c}
\sum r_{i} U\left(M_{i}\right) \\
\sum r_{i} U\left(M_{i}^{\prime}\right)
\end{array}\right\}
$$

In Eq. (3), $r_{i}$ is the surface ratio of element $i$ given by $S_{i} / S_{\text {total }}$ where $S_{i}$ and $S_{\text {total }}$ are the cross-sectional surface areas of element $i$ and the construction, respectively.

Finally, The transfer matrix $\mathbf{T}_{\mathbf{P}}$ of the parallel construction obtained by using Eqs. (2) and (3) is:

$$
\left\{\begin{array}{l}
P \\
U
\end{array}\right\}=\mathbf{T}_{\mathbf{p}}\left\{\begin{array}{l}
P^{\prime} \\
U^{\prime}
\end{array}\right\}=\frac{-1}{\Sigma r_{i} y_{i, 21}}\left(\begin{array}{cc}
\Sigma r_{i} y_{i, 22} \Sigma r_{i} y_{i, 11}-\Sigma r_{i} y_{i, 12} \Sigma r_{i} y_{i, 21} & -\Sigma r_{i} y_{i, 11}
\end{array}\right)\left\{\begin{array}{c}
P^{\prime} \\
U^{\prime}
\end{array}\right\}
$$

From this global matrix, absorption coefficient and sound transmission loss can be calculated by, respectively

$$
\alpha=1-\left|\frac{T_{p 11} \cos \Psi-T_{p 21} Z_{0}}{T_{p 11} \cos \Psi+T_{p 21} Z_{0}}\right|^{2} \text { and } S T L=20 \log _{10}\left(\frac{1}{2}\left|T_{p 11}+T_{p 22}+\frac{\cos \psi}{Z_{0}} T_{p 12}+\frac{Z_{0}}{\cos \psi} T_{p 21}\right|\right)
$$

\section{MATERIALS AND METHOD}

To obtain the transfer matrix of the patchwork construction, the transfer matrix of each element must be known. For the results presented in the next section, acoustic models were used: Johnson-Champoux Allard model with rigid frame case for porous materials ${ }^{1}$ and Atalla-Sgard model for perforated plate ${ }^{9}$. Table 1 depicts the main physical characteristics of porous materials and perforated plate used. The predictions of the TMM were systematically compared to virtual measurements obtained with a 3D acoustical FEM simulations using COMSOL software. A three-microphone method is used to get the virtual measurements ${ }^{8}$. In the FEM model on COMSOL, parabolic tetrahedral elements were used to mesh the different acoustic domains of the tube, and convergence of the results was verified in the frequency range of interest. The porous elements of the construction samples were modeled as equivalent fluids using complex sound speed $\left(c_{e q}=\omega / k_{e q}\right.$, where $\omega$ is the angular frequency) and dynamic density ( $\left.\rho_{\text {eq }}=Z_{c e q} k_{e q} / \omega\right)$ given by the Johnson-Champoux-Allard model. Also, the perforated plates were modeled as interior impedance using Atalla-Sgard model. 
TABLE 1. Physical properties of selected materials.

\begin{tabular}{lccccccc}
\hline \multicolumn{1}{c}{ Materials } & $\begin{array}{c}\text { Open } \\
\text { porosity }\end{array}$ & $\begin{array}{c}\text { Static } \\
\text { airflow } \\
\text { resistivity } \\
\left(\mathbf{N}_{\text {N.s.m }} \text { ) }\right.\end{array}$ & $\begin{array}{c}\text { Viscous } \\
\text { characteristic } \\
\text { length }(\boldsymbol{\mu m})\end{array}$ & $\begin{array}{c}\text { Thermal } \\
\text { characteristic } \\
\text { length }(\boldsymbol{\mu m})\end{array}$ & Tortuosity & $\begin{array}{c}\text { Perforation } \\
\text { diameter } \\
(\mathbf{m m})\end{array}$ & $\begin{array}{c}\text { Thickness } \\
(\mathbf{m m})\end{array}$ \\
\hline A Switchgrass & 0.774 & 3660 & 124 & 481 & 2.40 & - & - \\
B Glass wool & 0.999 & 15957 & 97 & 530 & 1.00 & - & - \\
C Melamine foam & 0.999 & 10900 & 100 & 130 & 1.02 & - & - \\
D Polyester fiber & 0.990 & 18428 & 88 & 722 & 1.00 & - & - \\
E Polyurethane foam & 0.958 & 11188 & 70 & 209 & 1.94 & - & - \\
F Rockwool & 0.960 & 41554 & 92 & 92 & 2.59 & - & - \\
G Perforated plate & 0.010 & - & - & - & - & 1 & 1 \\
\hline
\end{tabular}

\section{RESULTS}

\section{Parallel Construction of Six Materials under Oblique Incidence Acoustic Plane Wave}

The first construction studied is a rectangular assembly of $N=6$ materials in parallel under a $30^{\circ}$ incidence plane wave. The materials are switchgrass, glass wool, melamine foam, polyester fiber, polyurethane foam and rockwool corresponding to materials A, B, C, D, E and F of Table 1. Each material represents one sixth of the total surface and the rectangle is longitudinally split into sixth equal pieces. The construction is $25 \mathrm{~mm}$ thick. To respect assumption 3 of the TMM (no pressure diffusion between elements), each material is isolated by interior rigid walls. The FEM model for oblique incidence is shown in Fig. 2. A sample is excited by an oblique plane wave. Since the sample reacts locally (assumption 2), the wave is guided along the normal to its surface, comes out at the same incidence angle, and reflects on the rigid wall. This oblique incidence arrangement has already been used experimentally by Jun Mei et al. ${ }^{10}$ to estimate absorption coefficient of a metamaterial under oblique incidence plane wave; however, the transmission loss was not evaluated.

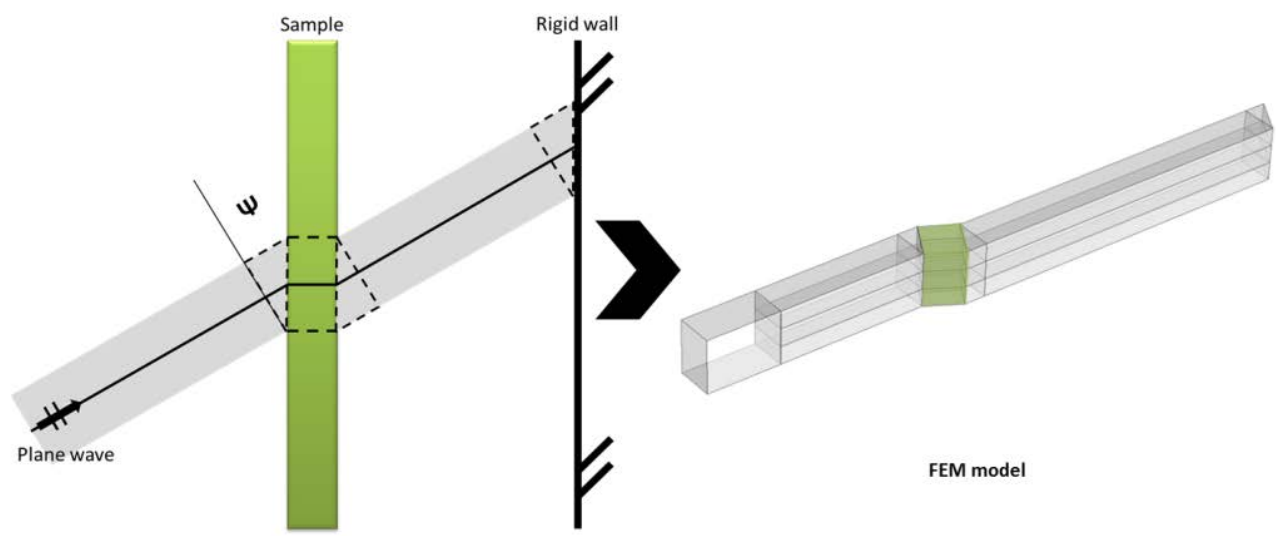

FIGURE 2. Schematic view of the oblique incidence impedance tube setup for the finite element model. The sample is a $3 \mathrm{x} 2$ rectangular assembly.

Figure 3 depicts the absorption coefficient and the transmission loss of this parallel construction as a function of frequency. One can notice that both acoustic properties obtained by the TMM are consistent with data predicted by the FEM simulation. However a divergence between the TMM and FEM data can be observed at frequencies above $2000 \mathrm{~Hz}$. This is due to the cutoff frequency of the tube. A modal analysis with the FEM model has confirmed this. To comfort the validity of the TMM, insets of acoustic properties of each material which composes the parallel assembly were added in figure 3 . As one can note, these properties are clearly different from those of the construction. 

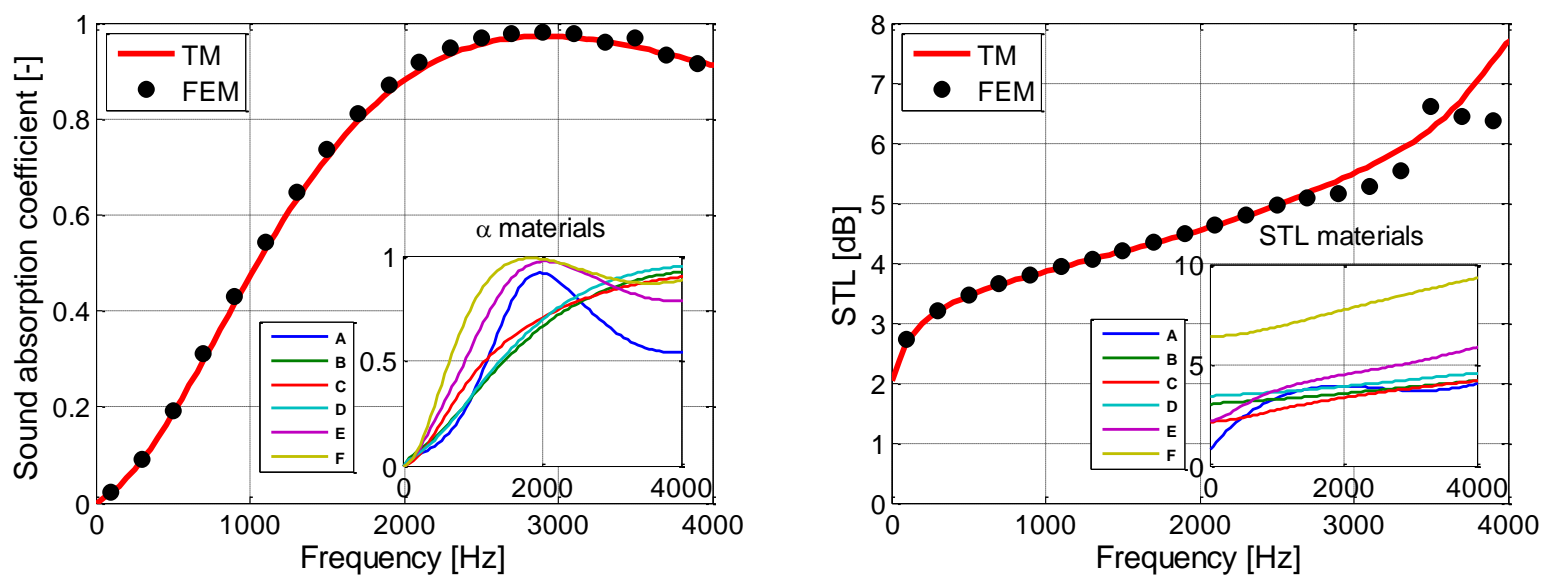

FIGURE 3. Oblique $\left(30^{\circ}\right)$ incidence sound absorption coefficient and transmission loss of the parallel assembly of six materials. Comparison between TMM and FEM results.

\section{Parallel versus Serial Arrangements of perforated plates}

In this part, parallel TMM is combined with series TMM. A parallel arrangement of two microperforated plate resonators (MPP) made of an assembly of a same perforated plate with two different air cavities is compared with a serial conventional construction of these resonators. The first resonator is made of a perforated plate, corresponding to $\mathrm{G}$ in table 1, with a $60 \mathrm{~mm}$ thick air cavity. The second is the same but the air cavity is $20 \mathrm{~mm}$ thick. Each element occupies $50 \%$ of the total surface. Figure 4 depicts the absorption coefficient and the transmission loss of this parallel MPP construction, the series arrangement of the first and second MPP resonators (Series 1), and the reverse of the series configuration (Series 2). One can notice that both acoustic properties obtained by the TMM are consistent with data predicted by the FEM simulation. The parallel resonator is comparable to the typical double degree of freedom resonator both with a smaller thickness $(61 \mathrm{~mm}$ instead of $82 \mathrm{~mm})$. A recent work by Wang and Huang ${ }^{11}$, deals with this kind of parallel resonator.

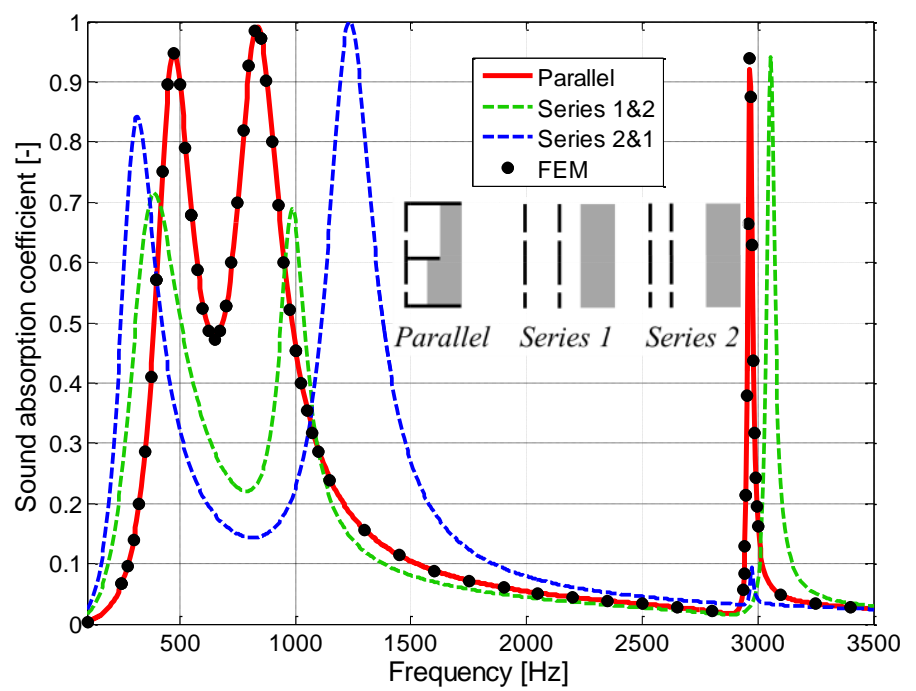

FIGURE 4. Normal incidence sound absorption coefficient of the MPP absorber array consisting of a MPP of $1 \%$ perforation ratio, $1 \mathrm{~mm}$ thick and $1 \mathrm{~mm}$ orifice diameter. The parallel MPP is backed by two parallel air gaps of thickness 20 and $60 \mathrm{~mm}$, respectively. The two series MPP used 60 and $20 \mathrm{~mm}$ air gaps, and 20 and $60 \mathrm{~mm}$ air gaps, respectively. 


\section{Simulation of 3D Configuration}

It was shown that series and parallel matrices can be combined in order to describe a sample made of heterogeneous layers. Thus a question arises: is it possible to describe a $3 D$ configuration with the parallel/series $T M M$ ? To answer this question, a volume can be discretized into elementary or representative volumes as in a finite element concept. The surface of each elementary volume can be decomposed into several parallel cells. To reconstruct the entire configuration, it is necessary to stack, in series, the elementary volumes describing several materials stacked in parallel. To illustrate this approach an example is presented below. It is an arrangement of 32 melamine spheres of $25 \mathrm{~mm}$ diameter in a cubic lattice as shown in Figure 5. Along the thickness axis, it is necessary to know the surface ratio of the melamine and the air. These surfaces are obtained by trigonometric relation:

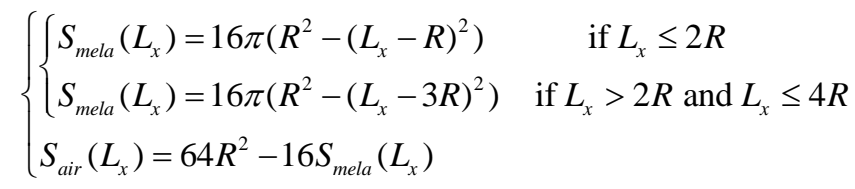

where $L_{x}$ is the penetration distance in the sample and $R$ is the sphere radius.

To yield convergence of the TMM, the sample was divided into 200 layers. A 3D FEM model was used to evaluate the absorption coefficient and the transmission loss of the spheres of melamine foam in series. Figure 5 presents the results obtained with TMM and FEM. Once again, both methods give similar results. The proposed approach could be referred to as an element transfer matrix method (ETMM). It is important to highlight that the computation time of this ETMM is a fraction of that of the FEM. Here, there are no rigid walls to ensure assumption 3. Indeed, there are no diffusion phenomena because the permeability contrast between melamine and air are weak, thus the plane wave is not disturbing. For more information, diffusion phenomena are studied by Olny et al. ${ }^{12}$.
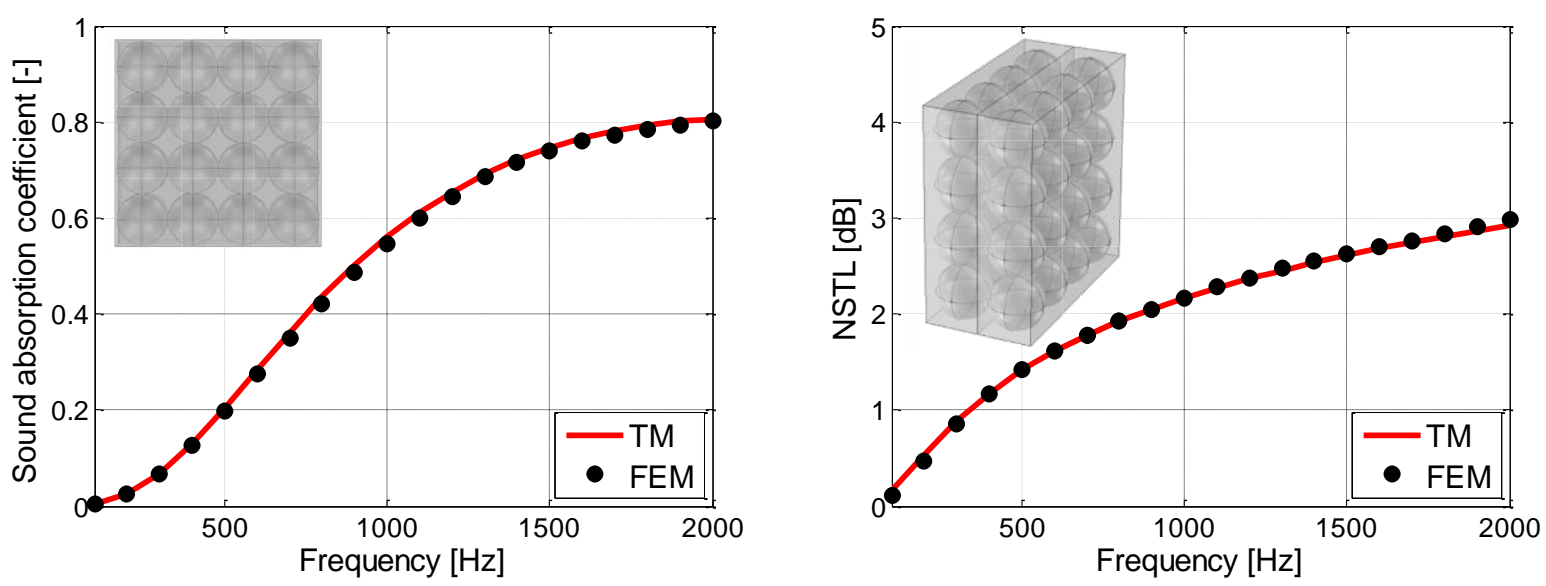

FIGURE 5. Normal incidence sound absorption coefficient and transmission loss of the assembly of 32 melamine spheres. Each sphere is $25 \mathrm{~mm}$ in diameter. Comparison between TMM and FEM results.

\section{CONCLUSION}

An extension to the transfer matrix method (TMM) was exposed to handle a parallel assembly of multiple elements. It was shown that the parallel TMM compares well with FEM results on 2D or 3D configurations. One of the key assumptions is that there is no pressure diffusion between adjacent parallel elements. In fact, for some conditions, the proposed method works. These conditions depend on many variables such as media size, surface ratio between media, contact shape and distribution of the first medium with regard to the second one. Some rules must be identified in future works. It is a first step to achieve a generalization of the TMM in order to take into account all acoustic phenomena and size effects. Such generalized TMM can be useful to optimize and analyze 
heterogeneous structured surfaces and volumes (ETMM) as encountered in acoustic metamaterials. More details on the work presented in this paper can be found in a recent paper by the authors ${ }^{7}$.

\section{ACKNOWLEDGMENTS}

This work was supported by grants-in-aid from the Natural Sciences and Engineering Research Council of Canada (N.S.E.R.C.).

\section{REFERENCES}

1. J.F. Allard and N. Atalla, Propagation of sound in porous media: modeling sound absorbing materials, 2nd ed. (Elsevier Applied Science, New York, 2009), pp. 243-307.

2. M. Yairi, K. Sakagami, K. Takebayashi and M. Morimoto, "Excess sound absorption at normal incidence by two microperforated panel absorbers with different impedance," Acoust. Sci. \& Tech. 32, 194-200 (2011).

3. N. K. Vijayasree and M. L. Munjal, "On an Integrated Transfer Matrix method for multiply connected mufflers," J. Sound Vib. 331, 1926-1938 (2012).

4. J. Wang, P. Leistner and X. Li, "Prediction of sound absorption of a periodic groove structure with rectangular profile," Appl. Acoust. 73, 960-968 (2012).

5. J. Ducourneau, L. Bos, V. Planeau, A. Faiz, S. S. Lami and A. Nejade, "Prediction of the acoustic pressure above periodically uneven facings in industrial workplaces," J. Sound Vib. 329, 2276-2290 (2010).

6. N. Atalla, R. Panneton and J. F. Allard, "Sound absorption by non homogeneous thin porous layers," Acta. Acust. Acust. 83, 891-896 (1997).

7. K.Verdière, R. Panneton, S. Elkoun, T. Dupont and P. Leclaire, "Transfer matrix method applied to the parallel assembly of sound absorbing materials," J. Acoust. Soc. Am, submitted (2012).

8. O. Doutres, Y. Salissou, N. Atalla and R. Panneton, "Evaluation of the acoustic and non-acoustic properties of sound absorbing materials using a three-microphone impedance tube," Appl. Acoust. 71, 506-509 (2010).

9. N. Atalla and F. Sgard, "Modeling of perforated plates and screens using rigid frame porous models," J. Sound Vib. 303, 195208 (2007).

10. J. Mei, G. Ma, M. Yang, Z. Yang, W. Wen and P. Sheng, "Dark acoustic metamaterials as super absorbers for low-frequency sound," Nat. Commun (2012).

11. C. Wang and L. Huang, "On the acoustic properties of parallel arrangement of multiple micro-perforated panel absorbers with different cavity depths," J. Acoust. Soc. Am. 130, 208-218 (2011).

12. X. Olny and C. Boutin, "Acoustic wave propagation in double porosity media," J. Acoust. Soc. Am. 114, 73-89 (2003). 